\title{
Impacts of chronic disease prevention programs implemented by private health insurers: a systematic review
}

Sithara Wanni Arachchige Dona ${ }^{1,2}$, Mary Rose Angeles ${ }^{1,2}$, Natasha Hall ${ }^{1,2}$, Jennifer J. Watts ${ }^{1,2}$, Anna Peeters ${ }^{1}$ and Martin Hensher ${ }^{1,2^{*}}$

\begin{abstract}
Background: Chronic diseases contribute to a significant proportion (71\%) of all deaths each year worldwide. Governments and other stakeholders worldwide have taken various actions to tackle the key risk factors contributing to the prevalence and impact of chronic diseases. Private health insurers (PHI) are one key stakeholders, particularly in Australian health system, and their engagement in chronic disease prevention is growing. Therefore, we investigated the impacts of chronic disease prevention interventions implemented by PHI both in Australia and internationally.

Method: We searched multiple databases (Business Source Complete, CINAHL, Global Health, Health Business Elite, Medline, PsycINFO, and Scopus) and grey literature for studies/reports published in English until September 2020 using search terms on the impacts of chronic disease prevention interventions delivered by PHIs. Two reviewers assessed the risk of bias using a quality assessment tool developed by Effective Public Healthcare Panacea Project. After data extraction, the literature was synthesised thematically based on the types of the interventions reported across studies. The study protocol was registered in PROSPERO, CRD42020145644.

Results: Of 7789 records, 29 studies were eligible for inclusion. There were predominantly four types of interventions implemented by PHIs: Financial incentives, health coaching, wellness programs, and group medical appointments. Outcome measures across studies were varied, making it challenging to compare the difference between the effectiveness of different intervention types. Most studies reported that the impacts of interventions, such as increase in healthy eating, physical activity, and lower hospital admissions, last for a shorter term if the length of the intervention is shorter.
\end{abstract}

Interpretation: Although it is challenging to conclude which intervention type was the most effective, it appeared that, regardless of the intervention types, $\mathrm{PHI}$ interventions of longer duration (at least 2 years) were more beneficial and outcomes were more sustained than those PHI interventions that lasted for a shorter period.

Funding: Primary source of funding was Geelong Medical and Hospital Benefits Association (GMHBA), an Australian private health insurer.

Keywords: Chronic diseases, Private health insurers, Prevention

\footnotetext{
* Correspondence: martin.hensher@deakin.edu.au

'Institute for Health Transformation, Faculty of Health, Deakin University,

Geelong, Victoria 3220, Australia

2Deakin Health Economics, School of Health and Social Development

Faculty of Health, Deakin University, Geelong, Victoria 3220, Australia
}

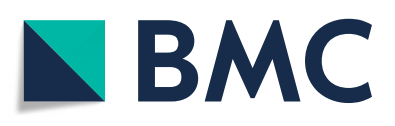

(c) The Author(s). 2021 Open Access This article is licensed under a Creative Commons Attribution 4.0 International License, which permits use, sharing, adaptation, distribution and reproduction in any medium or format, as long as you give appropriate credit to the original author(s) and the source, provide a link to the Creative Commons licence, and indicate if changes were made. The images or other third party material in this article are included in the article's Creative Commons licence, unless indicated otherwise in a credit line to the material. If material is not included in the article's Creative Commons licence and your intended use is not permitted by statutory regulation or exceeds the permitted use, you will need to obtain permission directly from the copyright holder. To view a copy of this licence, visit http://creativecommons.org/licenses/by/4.0/ The Creative Commons Public Domain Dedication waiver (http://creativecommons.org/publicdomain/zero/1.0/) applies to the data made available in this article, unless otherwise stated in a credit line to the data. 


\section{Introduction}

Worldwide, $71 \%$ (41 million) of all deaths each year are attributed to chronic diseases [1], with chronic diseases responsible for nine out of ten deaths in Australia [2]. Chronic or non-communicable diseases are illnesses that "tend to be of long duration and are the result of a combination of genetic, psychological, environmental and behavioural factors" [1]. Chronic diseases lead not only to deteriorating quality of life for individuals [3] but also cause an economic burden on individuals, health systems and wider society [4].

Governments and other stakeholders worldwide have taken a broad range of actions to tackle the key risk factors which contribute to the prevalence and impact of chronic diseases [5]. In Australia in 2011, it was estimated that $31 \%$ of the total burden of disease was potentially preventable through actions on 29 behavioural, metabolic, environmental and dietary risk factors [6]. Health insurers are one of the key stakeholders in health systems worldwide with the capacity to act on chronic disease prevention and management. While globally there are a number of different health insurance settings, such as private health insurance (PHI), employersponsored health plans, veteran's affairs and public health insurance [7], our focus in this study is on the emerging role of private health insurers in chronic disease prevention [8].

Globally, prepaid private health spending, which included PHI, accounted for $17.4 \%$ of total health financing in 2014 [9]. This varied across countries. For example, PHI spending accounted for $6.6 \%, 7.1 \%, 38.3 \%$, $44.2 \%$ of total health spending in New Zealand, UK, USA, South Africa respectively [9]. These differences reflect the fact that the scope, coverage and structure of PHI cover varies substantially between countries. Australia offers publicly funded universal health coverage for all citizens and permanent residents, through the national Medicare program and via the public health and hospital systems in each state and territory of the Federation. Yet PHIs play an important role in the Australian health system, accounting for some $9 \%$ of total health expenditure [10], especially in the funding of elective surgery and hospital care. However, in the Australian setting, PHI does not have full responsibility for the integrated care of insured members, most crucially because PHI is not permitted to fund primary health care and general practice [11]. Despite these constraints, interest in the role, incentives and ability of PHI to engage more closely in the prevention of chronic diseases is growing [12]. Action is growing not only in programs focused on primary and secondary prevention but also in selfmanagement, which plays a crucial role in managing chronic diseases successfully to prevent further occurrence of symptoms or further complications [13]. Chronic disease management (CDM) activities focus on people with already-diagnosed chronic conditions. Despite legislation permitting PHI funds to pay benefits for CDM services having been in place for more than 10 years in Australia, insurers are still in an early stage of implementation and evaluation of CDM activities. During a qualitative study in 2019, PHI representatives reported identifying target groups; evaluating service outcomes; and collaborating with other healthcare providers as challenges to providing appropriate CDM programs [11]. Nonetheless, PHI's role in chronic disease prevention and supporting people with chronic diseases to improve quality of life is emerging [11], through adopting chronic disease prevention interventions beyond the coverage of specific insurance products.

Previously there have been systematic reviews undertaken on financial incentives provided by both public and private health insurers for the prevention and management of overweight and obesity [7] and rapid or systematic reviews on chronic disease prevention interventions, but these were either focused on one kind of intervention or delivered by stakeholders other than PHI $[14,15]$. Therefore, the aim of this paper is to systematically review to summarise the impacts of chronic disease prevention interventions implemented by PHI both in Australia and internationally, in order to provide lessons on how PHI might engage most effectively with primary, secondary and/or tertiary prevention of chronic diseases.

\section{Methods}

\section{Search strategy}

This systematic review is reported following Preferred Reporting Items for Systematic Review and MetaAnalysis (PRISMA guidelines) [16], 2020 checklist (Additional File 1). We conducted a systematic literature search across seven online databases: Business Source Complete, CINAHL, Global Health, Health Business Elite, Medline, PsycINFO (APS PsycINFO), and Scopus. Additional relevant literature and grey literature (i.e. reports) were searched using Google, Google Advanced, and reference lists of the included articles. Search terms were developed around PHI and chronic disease prevention or health promotion programs (see Additional File 2).

Studies were included if they evaluated the impacts of chronic disease prevention interventions implemented by PHIs. Primary, secondary and tertiary prevention interventions are defined respectively as reducing the incidence of disease before onset; preventing diseases at very early stage from progressing; and managing the manifest disease and its complication to improve quality of life [17]. Studies on the impacts of chronic disease management programs by PHIs were also included if prevention strategies were incorporated. Studies published in English until September 2020 were included. The search was not limited to specified study designs or a population. 
Studies were excluded if they were on impacts of programs primarily not implemented by $\mathrm{PHI}$; or programs implemented by government funded public health insurers; or programs implemented by workplaces/employers with no sponsorship from PHI; or chronic disease care/treatment programs with no prevention strategies involved; or studies about expanded private health insurance coverage for various health conditions; or value based insurance designs (i.e. programs that provide reduced prescription drug co-payment costs for targeted chronic diseases). Studies published in languages other than English, abstracts, conference papers, newspaper articles, and study protocols were excluded.

\section{Study selection and data extraction}

The selection of studies during the screening process was based on the above eligibility criteria. Two reviewers (SWAD and $\mathrm{NH}$ ) first screened all the titles and abstracts independently using EndNote software. Selected papers were then divided equally between the two reviewers (SWAD \& NH) for full-text screening and crosschecked. Any disagreement in either of these steps was discussed with one other author of this paper $(\mathrm{MH})$ to reach a consensus. If full text articles were not found, they were retrieved by contacting Deakin University librarians via inter-library loan requests. Two reviewers (SWAD and $\mathrm{NH}$ ) independently extracted the following data on an Excel table: country, program name, description of the program, health insurer, target population (community/members), study design, time period of the study, sample, any outcome measure and results. The literature was synthesized thematically; no meta-analysis or statistical analysis was conducted due to wide heterogeneity of the intervention types and outcome measures reported in this literature. As this review is exploratory in nature, we summarised any outcomes that have been used in this area and effect measures as reported in studies. Summary results of the studies are provided in tabular forms in the text and as additional files. Given the heterogeneity and observational nature of studies, we used the available evidence as possible and did not attempt to assess the reporting bias or certainty of outcomes.

\section{Risk of bias and quality assessment}

For assessing risk of bias of included studies, two reviewers conducted the quality assessment independently (SWAD and MR). The review team discussed and resolved any discrepancies in the overall quality rating. The quality of selected studies was checked using the quality assessment tool for quantitative studies developed by Effective Public Healthcare Panacea Project (EPHPP), Canada [18]. We considered a range of tools for the assessment of risk of bias, including CASP, NIH, and STROBE; EPHPP was chosen due to the variety of methods and the quantitative nature of the included studies. The tool includes six components to rate study quality as Strong, Moderate or Weak. Studies that were rated strong were considered to have a low risk of bias, while weak studies were considered as having a high risk of bias.

\section{Results}

\section{Search results}

A total of 29 studies were included in the final thematic synthesis (Fig. 1). Table 1 provides the characteristics of the included studies. The majority of the studies were from the USA $(n=16,55 \%)$ followed by South Africa $(n=6,21 \%)$. The other countries were Australia $(n=5)$ and Germany $(n=2)$. Four studies were randomised controlled trials (RCT), but the majority of the studies were cohort studies $(n=14,48 \%)$. Other study designs were cross sectional $(n=6)$, case control $(n=2)$, mixed method $(n=1)$, a pre and post evaluation study $(n=1)$, and a systematic review $(\mathrm{n}=1)$.

Twelve studies (41\%) looked at the impacts of primary prevention measures delivered by PHI to reduce chronic diseases. Two studies evaluated the impacts of secondary prevention measures, and eleven studies were based on tertiary prevention measures. Three studies evaluated programs that incorporated mixed strategies of prevention levels such as both secondary and tertiary prevention (Table 2). The majority of the programs were for PHI members $(n=28,93 \%)$ while the others were at community level. Table 2 provides the description of interventions evaluated in the studies.

A summarised quality assessment of studies is presented in Additional File 3. The majority of studies ( $n=$ $24,83 \%$ ) were scored as having an overall weak quality in methodology according to the quality assessment tool for quantitative studies developed by EPHPP. Four studies were of moderate quality and only one study was rated as strong quality.

\section{Impacts of PHI chronic disease prevention programs}

This review identified four main categories of chronic disease prevention interventions being delivered by PHI. The selected studies were summarised based on these types: Financial incentives, health coaching, wellness programs, and group medical appointments. The outcomes and effect measures are varied across studies as summarised in this section (see Additional File 4).

\section{Financial incentives}

Nine studies were based on the impacts of financial incentives and focused on primary prevention [19-27]. Six studies evaluated Vitality program (Healthy Food program) by Discovery Health, which is one of the largest 


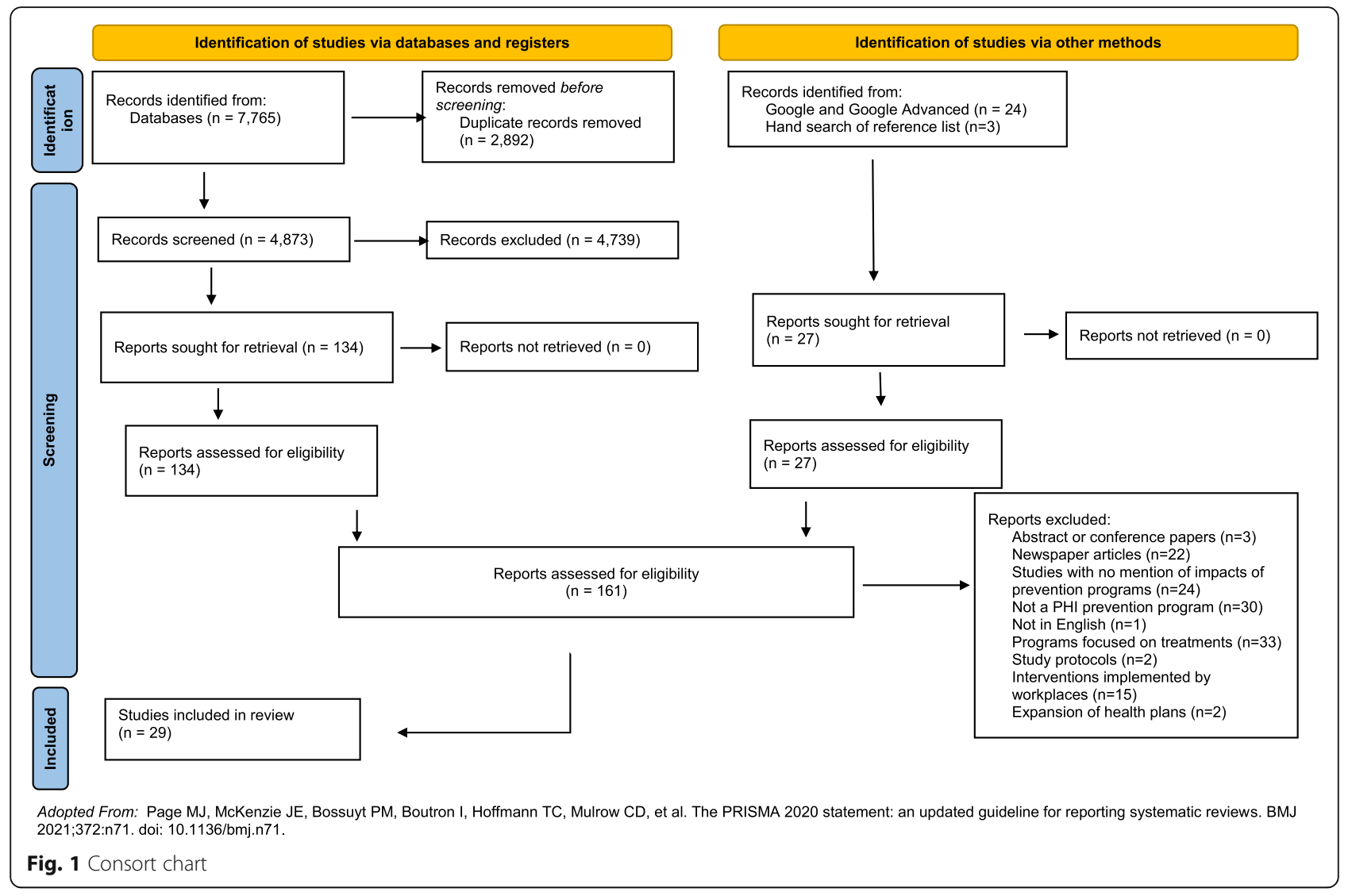

PHI (or "medical aid") funds in South Africa. Table 2 provides a description of the program. Eight of the studies were high risk of bias [19-24, 26, 27], and one was moderate risk of bias [25]. According to Sturm et al., 10\% and 25\% discounts on healthy food choices led to an increase in healthy/total food ratio of $6 \%$ and $9.3 \%$ as well as in fruit and vegetables/total food ratio by $5.7 \%$ and $8.5 \%$ respectively. A decrease in the ratio of less desirable/total food expenditure by $5.6 \%$ and $7.2 \%$ respectively [23]. A repeated survey of 350,000 participants and nonparticipants of HealthyFood program, which was part of Vitality, found out that subsidies on healthier foods significantly increased the purchase and consumption of promoted products [20]. Their study showed that discounts were associated with statistically significant positive changes in self-reported dietary behaviours compared to no discounts $(p<0.0001)$. Larger discounts were always associated with a larger effect compared to smaller discounts. Daily fruits and vegetable consumption increased by $40 \%$ and $60 \%$ for $10 \%$ and $25 \%$ discounts respectively. People (who receive $10 \%$ or $25 \%$ rebate) were twice and three times more likely to have three or more servings of wholegrain foods on a daily basis than no rebate. Similarly, people were $25 \%$ (10\% discount) and $65 \%$ (25\% discount) less likely to have foods high in sugar, as well as $40 \%$ (10\% discount) and $75 \%$ (25\% discount) less likely to have foods high in salt [20].
A longitudinal study on the incentivised Vitality program found a significant reduction in the prevalence of physical inactivity from 76 to $68 \%$ over a 5 -year period, which is a risk factor for chronic diseases. Increased physical activity was associated with reduced probability of hospital admissions due to chronic diseases [21]. Members who were highly active within the first 3 years had less hospital admissions in year 4 to 5 (20.7\%) compared to inactive members (22.2\%). Gym use increased from 27 to $33.1 \%$ over the 5-year period and for each two extra gym visits per week the likelihood of a hospital admission was reduced by $13 \%(\mathrm{OR}=.87 ; 95 \% \mathrm{CI} 0.801$, 0.949) [21]. Participants who were in the high active Vitality group (greater than 48 gym visits per year) had $35 \%$ less cancer and mental illness admissions than members in other groups. Admissions associated with endocrine, nutritional, metabolic disorders, kidney and urinary tract disorders were $20 \%$ lower compared with members in other activity groups. Admission rates were also $7.4 \%$ lower for cardiovascular disease, $13.2 \%$ lower for cancers [22].Another incentive based 4-month physical activity program, the ACHIEVE study, recruited inactive individuals aged 40-65 years via GMHBA in Australia and found that there were large increases in leisure time physical activity by $212.1 \mathrm{mins} /$ week in men from $106.7 \pm 135.1$ to $318.8 \pm 263.6(p$-value $<0.001)$ and 


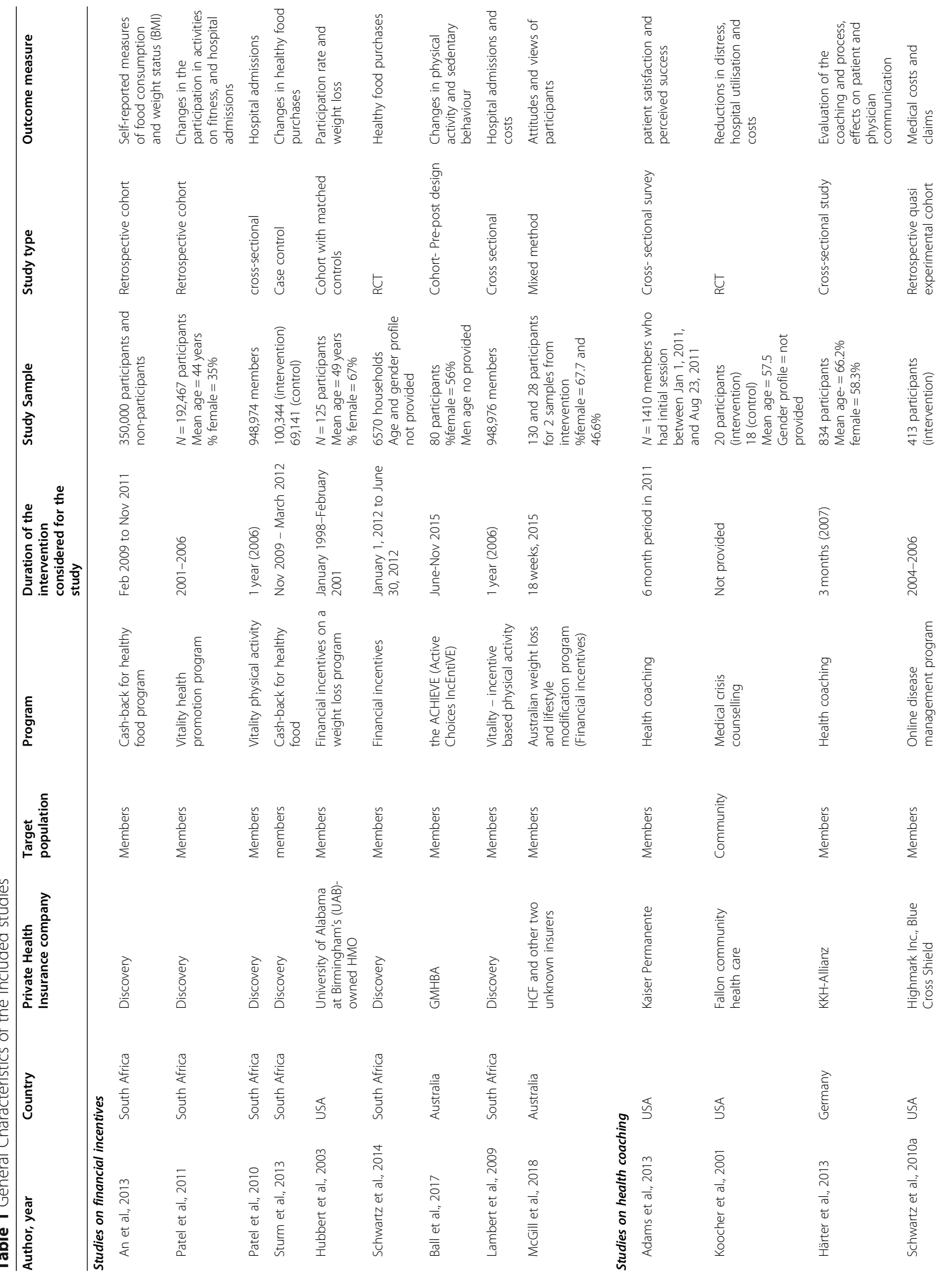




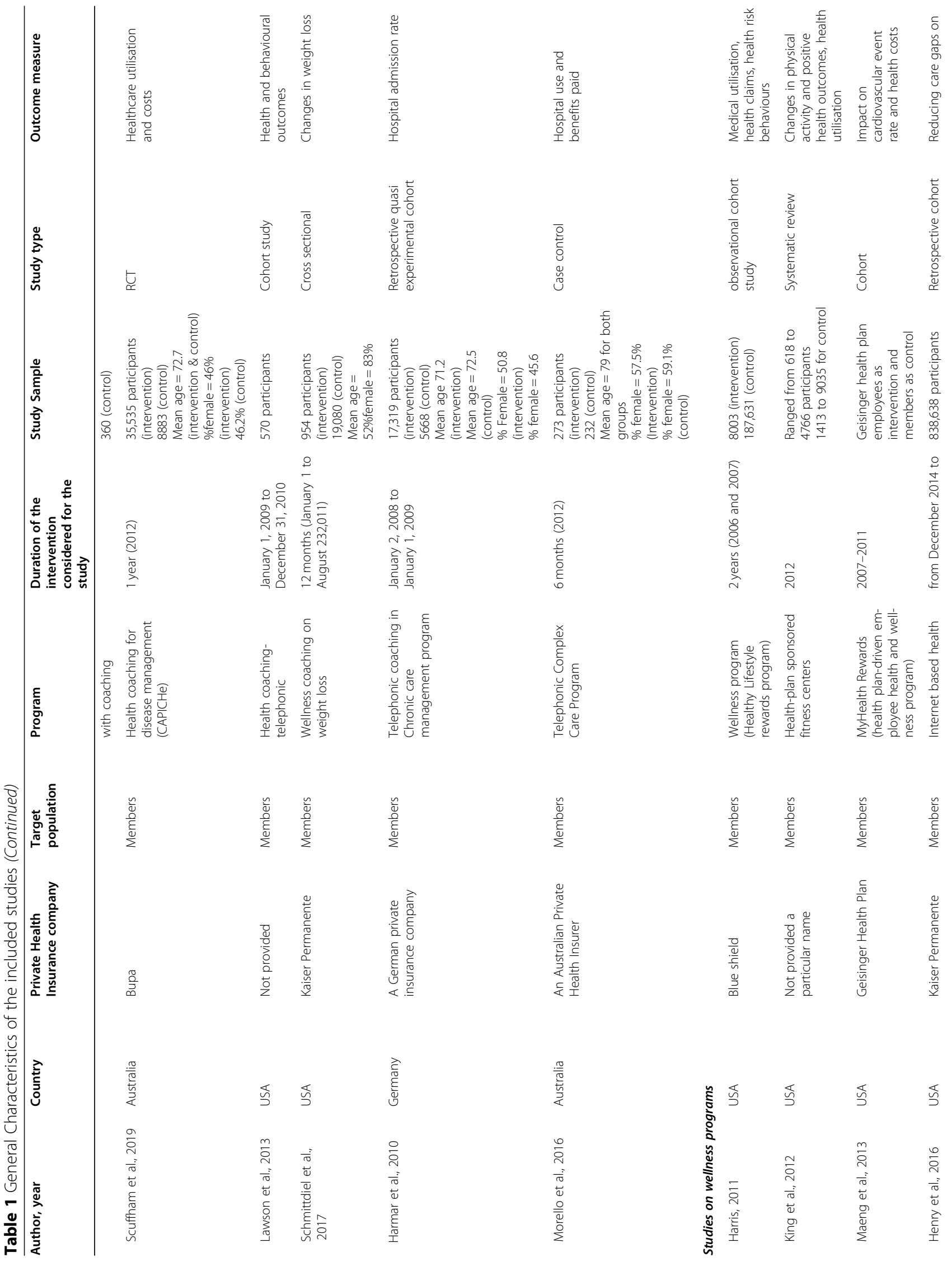




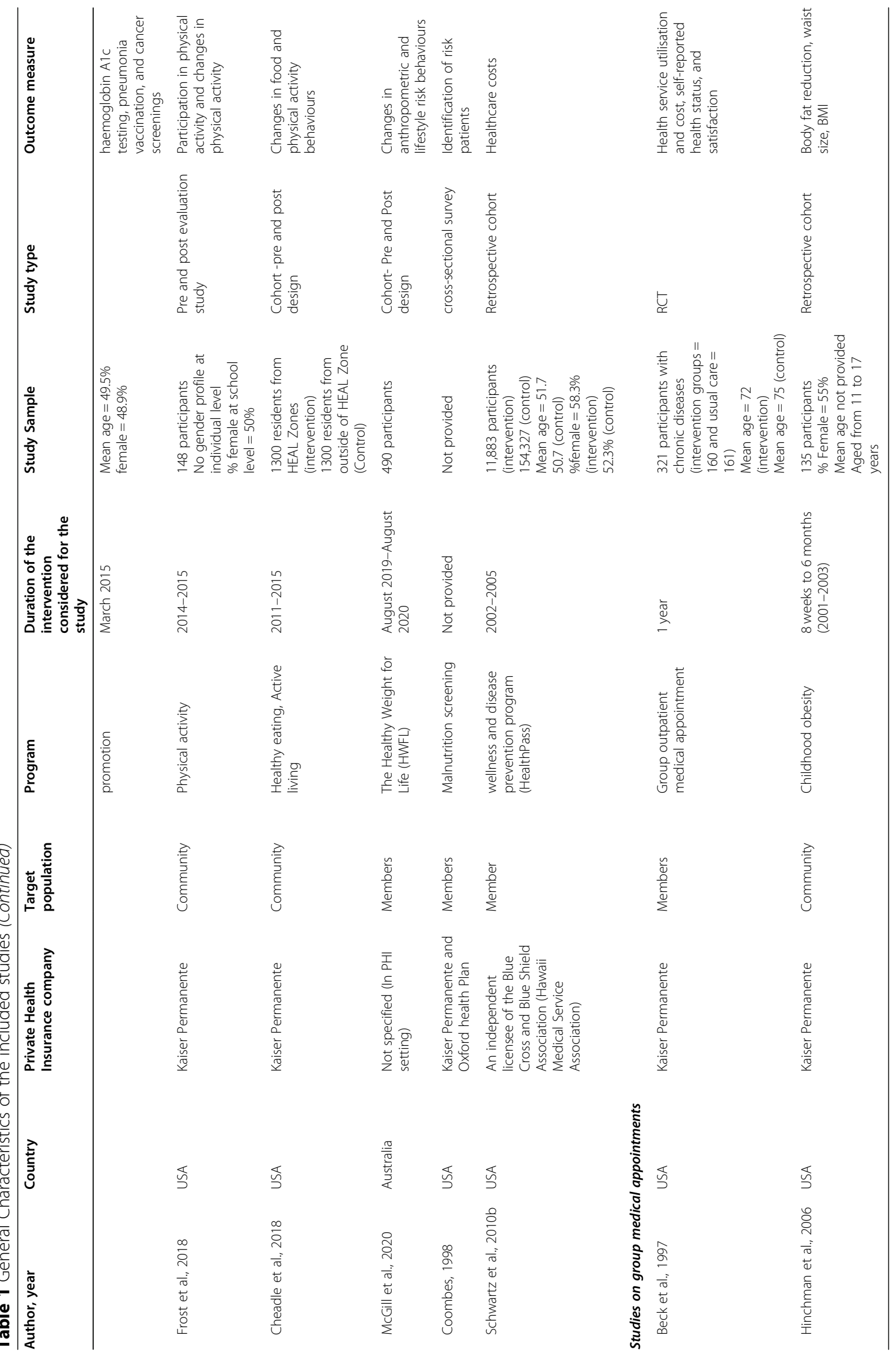


Table 2 Description of chronic disease prevention programs

\begin{tabular}{|c|c|c|c|c|}
\hline Author, year & $\begin{array}{l}\text { Health Insurance } \\
\text { company }\end{array}$ & Program & Program Description & Prevention Level \\
\hline \multicolumn{5}{|c|}{ Studies on financial incentives } \\
\hline An et al., 2013 & Discovery & $\begin{array}{l}\text { Financial incentives- } \\
\text { Cash-back for healthy } \\
\text { food }\end{array}$ & $\begin{array}{l}\text { The HealthyFood program offers members up } \\
\text { to } 25 \% \text { cash back on healthy food purchases } \\
\text { on an ongoing basis which has spread } \\
\text { nationwide across South Africa with about } \\
260,000 \text { enrolled households and } 800 \\
\text { supermarkets. }\end{array}$ & Primary prevention \\
\hline
\end{tabular}

Patel et al., $2011 \quad$ Discovery

Patel et al., 2010

Discovery

Sturm et al., 2013 Discovery

Hubbert et al., $2003 \quad$ University of

Alabama

at Birmingham's

(UAB)-owned HMO

Schwartz et al., 2014 Discovery

Ball et al., 2017

GMHBA

Lambert et al., 2009

Discovery

McGill et al., 2018 physical activity

HCF and other two
Vitality physical activity

Vitality health promotion program

Cash-back for healthy food (positive cash reimbursement)

Financial incentives on a weight loss program

Financial incentives (negative cash reimbursement)

the ACHIEVE (Active Choices IncEntivE) weeks. If one lost $6 \%$ or more of their initial

Vitality - incentive based unknown
Australian weight loss and lifestyle modification program (Financial incentives)
From 2001 to 2003, with a \$15 monthly family fee, participants are offered with a subsidised gym membership and access to other fitness centre chains, and receive points as discounts on good and services at 20 and $40 \%$.

In 2006, the Vitality program was based on activities on fitness, screening and health assessment, education and healthy choices. Cost for a family was about $\$ 10$. Participation allowed to gain points which could be used as discounts from 15 to $45 \%$ for a range of purchases and services.

Ongoing incentive program. Study was conducted over 31 months. Participants had an average of 10.9 months on $10 \%$ rebate and 14.3 months with the $25 \%$ rebate.

Incentives were given for a group lifestyle based weight management program for 12 weight and participated in more than 10 sessions, \$150 was received as reimbursement at the end of the program which was a half of the program fee paid by the member. EatRight weight management program which included mean plans with controlled calorie

Monthly HealthyFood cash-back bonus from Vitality program for a duration of 6 months was implemented and the incentive was $\$ 113$. The cost of groceries was $\$ 56$ per month per family to join the program. Participants also risk losing the previously received reimbursement. Monthly email feedback about \% of healthy items bought compared to baseline

Financial and non-financial incentives were given ranging from AUD\$7.50 to $\$ 50$ each (total value $\$ 193.50$ for women and $\$ 196.50$ for men); and a chance to win one of four Apple iPad Mini devices (lottery-based incentive), worth \$454. The intervention rewarded positive behaviors, motivating to increase physical activity and reduce sedentary behaviour, with the ultimate aim of achieving 150 min of physical activity per week, and a reduction of

150 min per week of sedentary time.

Primary prevention

Primary prevention

Primary prevention

Primary prevention

Primary prevention

Primary prevention

Vitality program was offered to members at about $\$ 12$ per family. The sample was members whose incentives had been effective for 12 months in 2006

The Healthy Weight for Life program delivered three six-week phases over 18 weeks for those with weight related chronic diseases. The phases included eating plans with controlled portion, recommendations for physical activities and tracking progress, motivation,
Primary prevention

Tertiary prevention 
Table 2 Description of chronic disease prevention programs (Continued)

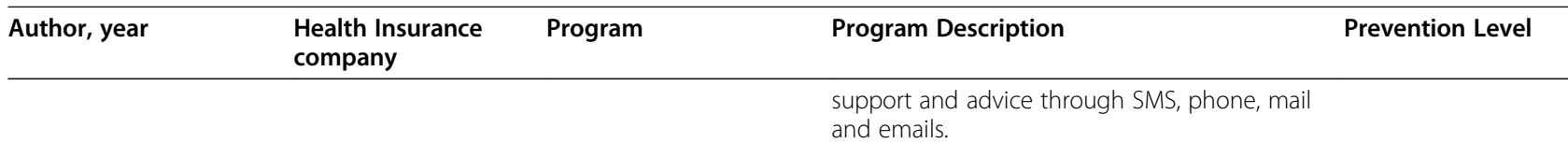

\section{Studies on health coaching}

Adams et al., 2013

Kaiser Permanente

Health coaching

Koocher et al., 2001

Fallon community health care

Medical crisis counselling

Härter et al., 2013

KKH-Allianz

Health coaching

Schwartz et al., 2010a

Highmark Inc., Blue Cross Shield

Scuffham et al., 2019

BUPA

Lawson et al., 2013
Wellness program through an online disease management program
Coaching Health (CAPICHe) trial

Health coachingtelephonic
A health coaching program through centralised telephonic Wellness Coaching Center across Kaiser Permanente Northern California which includes 48 medical facilities since January 2010. This was basically focused around motivational interviewing, which was a patient centred counselling style. This included one initial session for 20-20 min and a 10-20 min follow-up session. Coaching provided support with five lifestyle changes: healthy eating, physical activity, weight management, tobacco use cessation, and stress. Coaches record the session in participants' electronic medical record.

Medical crisis counselling service was offered for patients diagnosed with cancer to prevent related psychological issues. Patients were offered up to 10 sessions. The program focused on supporting to cope with the disease and distress. Patients charged \$2 per visit co-payment fee for each session.

Health coaching was offered for members with one or several chronic diseases. The coaching included goal attainment, information in medical conditions. The program is customised based on individual member such as monitoring weight, coaching on therapy adherence, and influenza vaccination

A Health Promotion and Disease Prevention Program was implemented for employees and members that included a set of online options, with health risk assessment, and online programs focused on managing healthy lifestyle, fitness, nutrition and stress, and tobacco cessation. This was part of the Blues on Call program, which is available for people with one or more chronic conditions. Telephone counselling delivered by registered nurses and dietitians was included, with interactive voice response telephonic outreach to members, letter and phone call reminders for clinical preventive exams, educational resources. Program began in September of 2004, along with an online chronic condition self-management intervention (HealthMedia ${ }^{\oplus}$ Care for Your Health) that works in conjunction with Blues on Call health coaches to help members manage chronic conditions.

Health coaching trial included programme awareness notifications, health Coaching session, and follow-up calls (from one call in the first 2 months with no maximum number of calls being set), accessing to health coaches via telephone as required and tailored outreach and educational materials.

Health coaching program was focused om health behaviour change, motivating and educating about self-management of the
Tertiary prevention

Tertiary prevention

Tertiary prevention

Tertiary prevention

Tertiary prevention

Tertiary prevention 
Table 2 Description of chronic disease prevention programs (Continued)

\begin{tabular}{|c|c|c|c|}
\hline Author, year & $\begin{array}{l}\text { Health Insurance } \\
\text { company }\end{array}$ & Program & Program Description \\
\hline & & & $\begin{array}{l}\text { disease. The program did not focus on diag- } \\
\text { nosis, treatment or complications or symptom } \\
\text { management, but on the physical, mental and } \\
\text { spiritual aspects of wellbeing. }\end{array}$ \\
\hline $\begin{array}{l}\text { Schmittdiel et al., } \\
2017\end{array}$ & Kaiser Permanente & Health coaching & $\begin{array}{l}\text { The health coaching program was for weight } \\
\text { management, physical activities and healthy } \\
\text { eating behaviours. The first session was for } \\
20-30 \text { min for speaking to coach on the } \\
\text { telephone, deciding on a health topic to } \\
\text { focus, assessing readiness to change, and } \\
\text { choosing an action step to begin. Follow-up } \\
\text { sessions are about } 10-15 \text { min based on re- } \\
\text { quest and should complete within a year or } \\
\text { less. }\end{array}$ \\
\hline Harmar et al., 2010 & $\begin{array}{l}\text { German private } \\
\text { insurance company }\end{array}$ & $\begin{array}{l}\text { Chronic care } \\
\text { management }\end{array}$ & $\begin{array}{l}\text { Chronic disease management program was } \\
\text { initiated in } 2008 \text { which is patient-centred ser- } \\
\text { vices that focused on the full scope of chronic } \\
\text { conditions, risk factors, and behaviours to sup- } \\
\text { port patients to treat the condition and man- } \\
\text { age their health. The program focused on } \\
\text { educating and empowering members such as } \\
\text { health-related behaviours, measures on self- } \\
\text { care, and adherence to care. This was mainly } \\
\text { facilitated by telephonic call support by } \\
\text { nurses) }\end{array}$ \\
\hline
\end{tabular}

Prevention Level

Morello et al., 2016 An Australian PHI Telephonic Complex Care Program

\section{Studies on wellness programs}

Harris, 2011

Blue shield

King et al., 2012

Maeng et al., 2013

$\begin{array}{ll}- & \text { Coverage of fitness } \\ & \text { centre membership } \\ & \text { (Fitness Sponsorship) }\end{array}$

Geisinger Health Plan
Wellness program (Healthy Lifestyle Rewards program-HLR))
The program was implemented on members with more hospital admissions. Program cost were included in the insurance membership. After a health assessment of risk, members were then offered with telephone support over six months, personalised care plan and referral to community based services. After the phone calls, a letter was sent which included information discussed in the call.

An online wellness program on modifiable risk factors such as physical activity, healthy food, smoking prevention and cessation, and stress. The program includes registration the HLR website, and completion of a health risk assessment (HRA) or Wellness Assessment questionnaire. Supplemental components of include logging into the HLR website at least once weekly and completing a wellness activity, and an on-site biometric screening of height, weight, among other markers. Participants can earn up to $\$ 200$ per year for participating. An individual earns $\$ 50$ for completion of the Wellness Assessment (step 2), and an additional $\$ 50$ for every 12 weeks logging into the HLR website and completes a wellnessrelated activity.

This systematic review was on health-plan sponsored fitness centre membership benefit (Known as the Silver Sneakers program)

Wellness program stated in July 2006. It included health risk assessment, Employees with the health plan membership were eligible for medications for hypertension, high cholesterol, and diabetes with $\$ 0$ co-pay to the employee, structures disease management programs along with financial incentives to participate. Participants received $\$ 200$
Tertiary prevention

Tertiary prevention

Tertiary prevention

Primary prevention

-

Primary prevention

Tertiary prevention (health plan-driven employee health and wellness program) 
Table 2 Description of chronic disease prevention programs (Continued)

\begin{tabular}{|c|c|c|c|c|}
\hline Author, year & $\begin{array}{l}\text { Health Insurance } \\
\text { company }\end{array}$ & Program & Program Description & Prevention Level \\
\hline & & & $\begin{array}{l}\text { incentive for enrolment and addition } \$ 200 \text { at } \\
6 \text { months, and another } \$ 200 \text { after one year } \\
\text { completion. The program was strategies for } \\
\text { self-management, nutrition and physical activ- } \\
\text { ity, medication management in collaboration } \\
\text { with the employee's primary care providers, } \\
\text { and acute exacerbation management. }\end{array}$ & \\
\hline Henry et al., 2016 & Kaiser Permanente & $\begin{array}{l}\text { Internet based health } \\
\text { promotion }\end{array}$ & $\begin{array}{l}\text { Kaiser Permanente Southern California offered } \\
\text { members an online Personal Action Plan with } \\
\text { a web portal to access to information about } \\
\text { prevention, health promotion, and care gaps. }\end{array}$ & $\begin{array}{l}\text { Secondary } \\
\text { prevention }\end{array}$ \\
\hline Frost et al., 2018 & Kaiser Permanente & Physical activity & $\begin{array}{l}\text { Kaiser Permanente Colorado's community } \\
\text { health initiated increased access to healthy } \\
\text { eating and active living in LiveWell Colorado. } \\
\text { Under this, a playground in intermediate } \\
\text { schools were redesigned and additional } \\
\text { equipment were added to encourage physical } \\
\text { activities. The study focused on monitoring } \\
\text { students at school before redesign in 2014, at } \\
6 \text { months and } 12 \text { months after the redesign. }\end{array}$ & Primary prevention \\
\hline Cheadle et al., 2018 & Kaiser Permanente & $\begin{array}{l}\text { Healthy eating, Active } \\
\text { living }\end{array}$ & $\begin{array}{l}\text { The healthy Eating Active Living (HEAL) Zones } \\
\text { obesity prevention initiative was delivered in } \\
2011-2015 \text { in } 12 \text { low-income communities in } \\
\text { Kaiser Permanente's Northern and Southern } \\
\text { California regions. HEAL Zones included pol- } \\
\text { icies, environmental and programmatic strat- } \\
\text { egies. For example, Providing a new physical } \\
\text { education curricula in kindergarten to 12th- } \\
\text { grade schools, installing a lighted walking trail } \\
\text { to provide access to safe physical activity, } \\
\text { healthy menus in restaurants, or media cam- } \\
\text { paigns on health education. The main differ- } \\
\text { ence between these two regions is the } \\
\text { duration where Northern area had two large } \\
\text { scale interventions with longer duration (one } \\
\text { from 20,006 to } 2010 \text { and the other is from } \\
2011 \text { to 2014). The Southern region had the } \\
\text { first phase of the program from } 2012 \text { to } 2016 \text {. } \\
\text { Second phase started in } 2016 \text {. }\end{array}$ & Primary prevention \\
\hline
\end{tabular}

McGill et al., $2020 \quad$ Not specified (In PHI The Healthy Weight for setting)

Coombes, 1998

Kaiser Permanente

Malnutrition screening

wellness and disease prevention program (HealthPass) Life (HWFL)
The program is an 18 week intensive weight loss and lifestyle modification program for those members who have $\mathrm{BMl}>28 \mathrm{~kg} / \mathrm{m} 2$ and those with a chronic disease. The program is offered remotely via phone, SMS, email, mail and online portal. The focus of the program is to support loss weight with controlled food portions, healthy eating for the first 12 weeks and recommendations for physical activities.

Oxford initiated the Nutrition screening program to identify at-risk members and managed them via both clinical and non-clinical interventions such as access to a nutrition visit from a contracted dietitian and follow-up visits.

HealthPass is a disease prevention and health promotion program implemented from 2002 to 2005 and started with a health risk assessment which assessed the member for lifestyle, habits, and health risks. Members also screened for biometric measures such as BMI, blood pressure, cholesterol, glucose. Other screenings such as pap smear were offered based on individual needs. There was a
Primary and Tertiary prevention

Secondary

prevention

Primary and secondary prevention
Cross and Blue Shield Association 
Table 2 Description of chronic disease prevention programs (Continued)

\begin{tabular}{|c|c|c|c|c|}
\hline Author, year & $\begin{array}{l}\text { Health Insurance } \\
\text { company }\end{array}$ & Program & Program Description & Prevention Level \\
\hline & & & $\begin{array}{l}\text { counselling session for each participant to } \\
\text { discuss risks, wellness goals and changes in } \\
\text { lifestyle. They were conducted individually or } \\
\text { as groups or over the phone. Online wellness } \\
\text { intervention program was implemented in the } \\
\text { final } 2 \text { years of the program on managing } \\
\text { weight, nutrition, stress and smoking } \\
\text { cessation. }\end{array}$ & \\
\hline \multicolumn{5}{|c|}{ Studies on group medical appointments } \\
\hline Beck et al., 1997 & Kaiser Permanente & $\begin{array}{l}\text { Group medical } \\
\text { appointment }\end{array}$ & $\begin{array}{l}\text { Monthly group visits for one year. The groups } \\
\text { visit included a } 15 \text { min warm up and } \\
\text { socialisation, } 30 \text { min health related information } \\
\text { presentation, } 15 \text { min of reviewing individual } \\
\text { patient's medical records, blood pressure } \\
\text { readings, determine any care needs by nurses } \\
\text { and attend patients when necessary by a } \\
\text { physician. Then, another } 15 \text { min for questions } \\
\text { and answers session. No changes made for } \\
\text { the usual care patients. }\end{array}$ & Tertiary prevention \\
\hline Hinchman et al., 2006 & Kaiser Permanente & Childhood obesity & $\begin{array}{l}\text { Operation Zero is a referral program for at risk } \\
\text { of overweight or overweight preadolescents } \\
\text { and adolescent patients. This involved group } \\
\text { medical appointments with weekly one-hour } \\
\text { appointments for two months and another } \\
\text { four appointments at three months intervals. } \\
\text { The program was family based and included } \\
\text { health education, activities and healthy } \\
\text { recipes. }\end{array}$ & $\begin{array}{l}\text { Secondary } \\
\text { prevention }\end{array}$ \\
\hline
\end{tabular}

$281.6 \mathrm{mins} /$ week in women from $81.4 \pm 105.3$ to $363.0 \pm$ 486.7 ( $p$-value $<0.001)$; transport related physical activity by $139.6 \mathrm{mins} /$ week in men from $73.4 \pm 85.8$ to $213.0 \pm$ 223.3 (p-value <0.001) and $207.1 \mathrm{mins} /$ week in women from $81.2 \pm 94.9$ to $288.3 \pm 371.4$ (p-value $<0.001)$. Sitting time reduced by $3.1 \mathrm{~h} /$ day for both genders from $8.6 \pm 2.6$ to $5.5 \pm 1.9$ for men (p-value $<0.001$ ) and from $8.4 \pm 2.4$ to $5.3 \pm 2.1$ for women ( $\mathrm{p}$-value $<0.001$ ). There were also reductions in BMI by $1.3 \mathrm{~kg} / \mathrm{m} 2$ (p-value < 0.001 ) and systolic blood pressure by $5.1 \mathrm{mmHg}$ [25].

Regarding the long term effects of incentives, after a weight loss and lifestyle modification program within three Australian insurance companies, participants of the program reported non-cash (i.e. incentive with a monetary value but not cash) (85.2\%) and cash (77\%) incentives would be a motivation, but $40.5 \%$ reported deposit contracts (i.e. making a monetary deposit which is refunded if weight loss is maintained) would motivate maintaining weight loss [27]. 93.9\% of respondents supported the idea of a maintenance program following the weight loss program. More than half of respondents were positive about providing financial incentives 3 to 6 months after the program. The majority $(85.2 \%)$ thought non-financial incentives would motivate maintaining weight loss [27].

\section{Health coaching}

Nine studies looked at the impacts of health coaching delivered by PHI [13, 28-35]. Eight studies were high risk of bias [13, 28-32, 34, 35], and one was moderate risk of bias [33]. In a health coaching program delivered by Kaiser Permanente, members who attended two or more sessions reported improvements compared to prior session they attended, such as having more healthy eating $(68 \%$ vs. $54 \%, p=0.04)$, increased physical activity (71\% vs. $45 \%, \mathrm{p}=<0.001)$, improved health $(79 \%$ vs. $61 \%, p=0.005)$, improved quality of life ( $83 \%$ vs. $61 \%$, $p<0.001$ ), and reduced risk of diseases (73\% vs. $51 \%$, $P=0.10$ ) [28]. Similarly, Lawson et al. found that telephonic health coaching significantly improved stress levels, healthy eating, exercise levels, physical and emotional health by $11.9 \%, 12.8 \%, 20.9 \%, 11.6 \%$ and $15.4 \%$ respectively [30]. General health status and quality of life was improved in all participants.

A randomised control study in a US Health Management Organisation (HMO) found that well-integrated mental health clinicians offering Medical Crisis Counselling (MCC) straight after a distressing diagnosis, (e.g., cancer or heart attack) found significant reductions in stress, anxiety and depression, increased patient satisfaction and increased perceived social support. Over the 6 
months of the study, no increases in overall medical costs were found but some decreased mental health utilization and costs were noted with MCC use. Favourable patient outcomes were seen regardless of the number of MCC sessions and therefore the costefficiency of the MCC approach was described by the authors as "impressive" [29].

Schwartz et al. also looked at cost impact of Blues on Call program with telephone outreach to members with chronic disease started by Blue Cross Blue Shield in Pennsylvania. An economic evaluation found the health care costs per person per year were $\$ 757$ less than predicted for participants undertaking 'Blues on Call' compared with matched non-participants. This equated to a return on investment of $\$ 9.89$ for every dollar spent on the program [35]. The intervention group had significantly lower same-day admission costs and fewer same-day admissions per 1000 personyears. The health coached group also had significantly fewer hospital admissions for patients with COPD and fewer same-day admissions for patients with diabetes. The Blues on Call program also had significant differences in service utilisation for total number of services, professional services, and pharmacy services $(p<.05)$. Patients had fewer total inpatient days and shorter length of stay per person per year and showed a declining trend from 2005 to 2007 [35]. However, Bupa Australia reviewed their health coaching program and found the total cost 1 year postrandomisation of health coaching compared to standard care was not significantly different [34]. Harmar et al. reported on a chronic disease program which incorporated telephonic outreach by nurses to members regarding selfcare measures and educating on health-related behaviours and adherence to care by a German PHI [32]. After oneyear of the intervention, the hospital admission rate decreased by $6.2 \%$ for the intervention group compared to the control group with a $14.9 \%$ increase $(p<0.001)$. The admission rate was recorded to be lower with but the number of telephone calls higher $(p=0.004)$ [32]. Nonetheless, another evaluation of the telephonic complex care program over 6 months in the Australian context (no name given for the $\mathrm{PHI}$ ) found there was no significant difference in the number of hospital admissions or total hospital days between both participants and non-participants in the 12 months after the intervention [33].

Moreover, a study on health coaching by German PHI, $\mathrm{KKH}-$ Allianz, found that $78 \%$ of members were satisfied with coaching and $82 \%$ would recommend it to others [13]. More than half the participants discovered new options, via health coaching, to influence their health condition [13].

\section{Wellness programs}

There were nine studies on wellness programs delivered by PHIs [36-44].Eight studies are high risk of bias
[36, 37, 39-44], and one study is moderate risk of bias [38]. One US study examined the impacts of the Blue Shield California's Internet based Wellness program (Healthy Lifestyle Rewards) and participants in wellness programs exercised more frequently, consistently ate more fruits and vegetables, and reported lower stress levels. They revealed that it was associated with statistically significant declines in all measures of outpatient utilization (including non-hospital physician and nonphysician visits, and physician visits) in the following year. There were no significant effects on claims spending for cholesterol and depression medications, or in utilization in the categories of emergency department visits, and inpatient admissions [37].

Schwartz and colleagues evaluated a 4 year wellness and disease prevention program called 'HealthPass' and estimated a net savings of $\$ 374, \$ 34, \$ 132$, and $\$ 124$ per year per participant yielding an estimated return on investment of $\$ 2.83, \$ 1.16, \$ 1.56$, and $\$ 1.58$ for every dollar invested for the years of 2002-2005, respectively [44]. Similar to the health care expenditures, nonparticipants made more claims for inpatient and pharmacy services $(p<0.0001$ for all years) compared to participants, who made more claims for medical services ( $p<0.0001$ for all years). The outpatient claims were not significantly different between the two groups $(p>0.10$ for all years). HealthPass participants consistently had fewer inpatient days per year and shorter average length of stay per admission compared to non-participants. Another study on 'MyHealth Rewards', an employee healthplan driven health and wellness program in the USA, showed that on average program participants experienced heart problems later than non-participants did $(p<0.01)$. This corresponded with a 10 to $13 \%$ cost reduction during the 2nd and 3rd year of the program [40]. Similarly, a systematic review on health-plan sponsored fitness centres showed a significant healthcare cost saving after a 2 years through reduced hospital admissions ( $\$ 500 ; 95 \% \mathrm{CI} \$ 892$ to $106, \mathrm{P}=0.01$ ) compared to a 1 year which had no difference between participants and non-participants of the program [39].

Another wellness intervention by PHIs was screening programs. Oxford Health Plan initiated a nutrition screening program to screen at-risk members and offer interventions related to nutrition such as visits from a dietitian and follow-ups. This program was able to reduce the nutrition risk and led to reduction in the number of insurance claims and emergency department visits, resulting in a $538 \%$ return on the investment [41].

Coombs et al. indicated that at a cost of only 21 cents per member per month for malnutrition screening, they found reduced insurance claims, reduced claim dollars, and reduced ED visits after implementation of nutrition screening [41]. Another approach to wellness was the 
Kaiser Permanente Online Personal Action Plan (oPAP), using the member web portal to better enable members to access information about prevention, health promotion, and care gaps. Users of oPAP were more likely than non-registered members to close healthcare gaps, especially cancer screening tests [38].

As a community initiative, Kaiser Permanente updated community playgrounds and found that children engaging in moderate to vigorous physical activity during recess increased by $23.3 \%(p<0.01)$, and the percentage engaged in vigorous physical activity increased by $26.2 \%$ [36]. These increases were sustained at 1 year from baseline. Cheadle et al's study on a community level 'Healthy Eating Active Living Zones' initiative also indicated that positive changes in diet and physical activity within population can be seen when the intervention is delivered to a larger number of people for a longer duration.

\section{Group medical appointments}

There were two studies that incorporated group medical appointments with prevention strategies, such as education and improving self-care measures [45, 46]. One study was high risk of bias [46] while the other one was low risk of bias [45]. Beck et al. evaluated the impact of PHI initiated group medical visits (which included health education, socialisation opportunities, mutual support, and prevention measures) on hospital utilisation and costs for chronically ill older members compared with standard care [45]. They found that after 1 year members in the intervention arm had less emergency department visits $(p=0.009)$, less specialist visits $(p=-.028)$ and less hospital admissions $(p=0.051)$, instead they made more nurse calls $(p=0.038)$ and fewer physician calls $(p=$ $0.019)$ than the control group. Average cost saving per participant of the intervention was \$14.79. Moreover, after a year, a greater percentage of intervention participants received vaccinations for influenza and pneumonia and had a greater satisfaction with care compared to the control group ( $81 \%$ vs. $64 \%$ ) [45]. Another program that utilised group medical appointment and education was Operation Zero (O.Z.) in paediatric obesity [46]. At 8 weeks after program completion compared with baseline, there were significant reductions in the percentage of body fat and waist size for those who attended 6 or more sessions. The program showed effectiveness after 6 months for weight maintenance, but not after 1 year. After 1 year, the mean change in weight and BMI in the O.Z. group was not statistically different compared to the control group [46].

\section{Discussion}

In recent years, there has been a growing interest in prevention of chronic diseases within the PHI setting. Many chronic disease prevention interventions have been delivered by PHIs in many countries. However, to the best of our knowledge, a systematic review has not yet been conducted on the impact of these interventions, and this is the first systematic review that explored the impact of variety of chronic disease prevention interventions implemented by PHIs. Twenty-nine studies were included in our final thematic synthesis.

Our results confirmed earlier systematic reviews on chronic disease prevention programs in different settings [15], highlighting that these interventions are generally effective in reducing risk factors of chronic diseases. The studies in our review had evaluated interventions for various outcome measures. While some studies measured healthy behaviour or weight loss as outcomes, other studies measured healthcare utilization or a mix of both. This review showed that the most studies were about health coaching, wellness programs and incentives, which could indicate that these intervention types were the most commonly used by PHIs.

Studies on health coaching found them to be effective in improving healthy eating, physical activity, quality of life, and reducing hospital utilisation [28]. However, the duration of effects was different for each intervention. Incentive programs were shown to increase healthy food consumption, and to achieve a statistically significant difference in self-reported dietary behaviours. However, An et al. concluded that there was no evidence to support the association between Vitality incentive programs for healthy food and reducing BMI or preventing obesity, despite self-reported reductions on BMI [20]. This shows the need for evaluating such programs by using measured BMI as an outcome measure in future studies. Vitality program interventions that were based on activities around fitness, screening and health assessment, education and healthy choices showed evidence of increased use of gym and physical activities. However, more than two-thirds of members still failed to use their gym benefits in a meaningful way for health improvement, suggesting that the incentives and subsidy are not sufficient to overcome behavioural inertia in a majority of members.

Regardless of the intervention types, it appeared that PHI interventions that of longer duration (more than 2 years) were more beneficial and outcomes were more sustainable than those PHI interventions that lasted for a shorter period. For example, incentive programs showed higher achievements in the short term: the 4month incentive program by GMHBA indicated a statistically significant difference in increase of leisure time physical activities, transport related physical activities, reduced sitting time and BMI at the end of 4 months. However, once incentives ceased, these impacts also reduced or were lost in the long run. This pattern was visible for both health coaching and wellness programs. 
King et al. also mentioned that a significant healthcare cost reduction due to reduced hospital admission was visible by the end of a 2 year fitness program, but the participation rates were starting to decline in the program's second year, with only $61 \%$ of participants continuing to participate [39].

Group medical appointments also indicated the same pattern of short-term improvements which were harder to sustain. While group medical appointments for weight loss management were shown to be effective after a year in reducing hospital utilisation and costs, and the changes were statistically significant, they were not effective for weight loss management after a year. For example, the O.Z. program was effective after 6 months, but after a year the mean change in weight and BMI of O.Z. participants were no longer statistically different to those of the control group. These results indicate that PHI group medical appointment programs can produce positive outcomes in the shorter term, but do not usually offer sustainable, long-term benefits once the intervention ceases.

The strengths of this systematic review are: the search of both academic and grey literature; and that the search was not limited to one geographical area or population. The limitations include: diversity of the interventions, methodology, and outcome measures of studies made comparability across interventions and outcomes challenging. Studies comparing different intervention types were not found, and the outcomes presented across the studies were varied and not sufficiently comparable to allow any decision on which intervention is the most effective. Many of the included studies were likely to have a high risk of bias, and therefore there is a need for future research to evaluate chronic disease prevention interventions by PHIs to establish their effectiveness and cost effectiveness in real practice settings.

\section{Implications and conclusion}

Chronic disease prevention interventions by $\mathrm{PHI}$, such as the Vitality program, health coaching, wellness programs, financial incentives and group medical appointments, have been shown to generate measurable health benefits for participants. Discovery Health and its Vitality program stand out as having made a particularly innovative contribution both in the design and the evaluation of interventions in this field. The results of this review show that all these approaches to chronic disease prevention by PHIs have been shown to be effective in the short term, but their impacts did not last in the long run once the intervention was ceased. It therefore seems likely that PHI prevention programs must themselves be sustained for long periods if their beneficial outcomes are also to be sustained. Future research should therefore focus on how best to design and deliver programs and interventions to achieve sustained behaviour change over long periods. This research shows that PHI insurers do have the potential to play a significant and beneficial role in improving the health of their members and the wider community, but only if they can take a longer-term perspective and act as "patient investors" in health and well-being.

\section{Other information}

The study protocol was registered in PROSPERO (CRD42020145644) [47] and can be accessed via https:// www.crd.york.ac.uk/PROSPERO/. The protocol was amended to include a researcher who contributed to the study and to update the completion date.

\section{Supplementary Information}

The online version contains supplementary material available at https://doi. org/10.1186/s12913-021-07212-7.

\section{Additional file 1. \\ Additional file 2. \\ Additional file 3. \\ Additional file 4.}

\section{Acknowledgements}

We would like to Thank our Deakin University librarians for their support in the development of search strategies and in finding full text articles.

\section{Authors' contributions}

SWAD and NH initiated the conceptualization of the study design and led the systematic review. SWAD and $\mathrm{NH}$ conducted the title and abstract review, full text review, data extraction under the guidance of $\mathrm{MH}$. SWAD and MRA conducted the quality assessment under guidance of MH. SWAD, $\mathrm{NH}, \mathrm{MRA}$ and $\mathrm{MH}$ did manuscript writing and preparation. All senior reviewers (JJW, AP and $\mathrm{MH}$ ) reviewed all the drafts. All authors have read and approved the final manuscript.

\section{Funding}

We gratefully acknowledge funding received from Geelong Medical and Hospital Benefits Association (GMHBA), an Australian private health insurer, for undertaking this review of the evidence related to chronic disease prevention interventions implemented by private health insurers in Australia and worldwide.

Availability of data and materials

All data generated or analysed during this study are included in this article and its additional files.

\section{Declarations}

Ethics approval and consent to participate Not applicable.

Consent for publication

Not applicable.

Competing interests

All authors declare that they have no competing interest. 
Received: 27 July 2021 Accepted: 21 October 2021

Published online: 11 November 2021

\section{References}

1. World Health Organization. Noncommunicable diseases. 2018. https://www. who.int/news-room/fact-sheets/detail/noncommunicable-diseases. Accessed 25 Feb 2021.

2. Moodie AR, Tolhurst $P$, Martin JE. Australia's health: being accountable for prevention. Med J Aust. 2016;204(6):223-5. https://doi.org/10.5694/mja15.00968.

3. Preto O, Amaral O, Duarte J, Chaves C, Coutinho E, Nelas P. Quality of life and chronic disease in patients receiving primary health care. 2nd International Conference on Health and Health Psychology; 2019.

4. Bloom DE, Chen S, Kuhn M, McGovern ME, Oxley L, Prettner K. The economic burden of chronic diseases: estimates and projections for China Japan, and South Korea. J Econ Ageing. 2020;17:100163.

5. Beaglehole R, Bonita R, Horton R, Adams C, Alleyne G, Asaria P, et al. Priority actions for the non-communicable disease crisis. Lancet. 2011;377(9775): 1438-47. https://doi.org/10.1016/S0140-6736(11)60393-0.

6. Barnes T. Australian burden of disease study: impact and causes of illness and death in Aboriginal and Torres Strait islander peoples, 2011; 2016.

7. Ananthapavan J, Peeterson A, Sacks G. Paying people to lose weight: the effectiveness of financial incentives provided by health insurers for the prevention and management of overweight and obesity - a systematic review: Wiley; 2018.

8. Mattke S, Mengistu T, Klautzer L, Sloss EM, Brook RH. Improving Care for Chronic Conditions: current practices and future trends in health plan programs. Rand Health Q. 2015;5(2):3.

9. Dieleman J, Campbell M, Chapin A, Eldrenkamp E, Fan W, Haakenstad A, et al. Evolution and patterns of global health financing 1995-2014: development assistance for health, and government, prepaid private, and out-of-pocket health spending in 184 countries. Lancet. 2017;389(10083): 1981-2004. https://doi.org/10.1016/S0140-6736(17)30874-7.

10. Australian Institute of Health Welfare. Health expenditure. Canberra: AlHW; 2020. https://www.aihw.gov.au/reports/australias-health/health-expenditure. Accessed 20 Feb 2021

11. Khoo J, Hasan H, Eagar K. Emerging role of the Australian private health insurance sector in providing chronic disease management programs: current activities, challenges and constraints. Aust Health Rev. 2019;43(5): 572-7. https://doi.org/10.1071/AH18164.

12. Biggs A. Chronic disease management: the role of private health insurance. Research paper (Parliamentary Library) ISSN 1834-9854; 2013.

13. Härter $M$, Dwinger $S$, Seebauer $L$, Simon D, Herbarth $L$, Siegmund-Schultze $E$, et al. Evaluation of telephone health coaching of German health insurants with chronic conditions. Health Educ J. 2013;72(5):622-34. https://doi.org/1 $0.1177 / 0017896912453990$.

14. Bellew B. Primary prevention of chronic disease in Australia through interventions in the workplace setting: a rapid review. Sax Institute for the Chronic Disease Prevention Unit, Victorian Government Department of Human Services; 2008.

15. Reynolds R, Dennis S, Hasan I, Slewa J, Chen W, Tian D, et al. A systematic review of chronic disease management interventions in primary care. BMC Family Practice. 2018;19(1):1-13. https://doi.org/10.1186/s12875-017-0692-3.

16. Page MJ, McKenzie JE, Bossuyt PM, Boutron I, Hoffmann TC, Mulrow CD, et al. The PRISMA 2020 statement: an updated guideline for reporting systematic reviews. BMJ. 2021;372:n71. https://doi.org/10.1136/bmj.n71

17. Solomon A, Mangialasche F, Richard E, Andrieu S, Bennett DA, Breteler M, et al. Advances in the prevention of Alzheimer's disease and dementia. J Intern Med. 2014;275(3):229-50. https://doi.org/10.1111/joim.12178.

18. Effective Public Health Practice Project. Quality Assessment Tool for Quantitative Studies. 2009. http://www.ephpp.ca/tools.html. Accessed 02 Nov 2020.

19. Hubbert K, Bussey B, Allison D, Beasley T, Henson C, Heimburger D. Effects of outcome-driven insurance reimbursement on short-term weight control. Int J Obes Relat Metab Disord. 2003;27(11):1423-9. https://doi.org/10.1038/sj. ijo.0802403.

20. An R, Patel D, Segal D, Sturm R. Eating better for less: a National Discount Program for healthy food purchases in South Africa. Am J Health Behav. 2013;37(1):56-61. https://doi.org/10.5993/AJHB.37.1.6.

21. Patel D, Lambert EV, Da Silva R, Greyling M, Kolbe-Alexander T, Noach A, et al. Participation in fitness-related activities of an incentive-based health promotion program and hospital costs: a retrospective longitudinal study.
Am J Health Promot. 2011;25(5):341-8. https://doi.org/10.4278/ajhp.100603QUAN-172.

22. Patel DN, Lambert EV, Da Silva R, Greyling M, Nossel C, Noach A, et al. The association between medical costs and participation in the vitality health promotion program among 948,974 members of a south African health insurance company. Am J Health Promot. 2010;24(3):199-204. https://doi. org/10.4278/090217-QUAN-68R2.1.

23. Sturm R, An R, Segal D, Patel D. A cash-Back rebate program for healthy food purchases in South Africa: results from scanner data. Am J Prev Med. 2013;44(6):567-72. https://doi.org/10.1016/j.amepre.2013.02.011.

24. Schwartz J, Mochon D, Wyper L, Maroba J, Patel D, Ariely D. Healthier by Precommitment. Psychol Sci. 2014;25(2):538-46. https://doi.org/10.1177/ 0956797613510950

25. Ball K, Hunter RF, Maple J-L, Moodie M, Salmon J, Ong K-L, et al. Can an incentive-based intervention increase physical activity and reduce sitting among adults? The ACHIEVE (active choices IncEntiVE) feasibility study; 2017

26. Lambert EV, da Silva R, Fatti L, Patel D, Kolbe-Alexander T, Derman W, et al. Fitness-related activities and medical claims related to hospital admissions South Africa, 2006. Prev Chronic Dis. 2009;6(4):A120.

27. McGill B, O'Hara BJ, Grunseit AC, Bauman A, Osborne D, Lawler L, et al. Acceptability of financial incentives for maintenance of weight loss in midolder adults: a mixed methods study. BMC Public Health. 2018;18:244.

28. Adams SR, Goler NC, Sanna RS, Boccio M, Bellamy DJ, Brown SD, et al. Patient satisfaction and perceived success with a telephonic health coaching program: the natural experiments for translation in diabetes (NEXT-D) study, northern California, 2011; 2013.

29. Koocher GP, Curtiss EK. Medical crisis counseling in a health maintenance organization: preventive intervention. Prof Psychol Res Pr. 2001;32(1):52-8. https://doi.org/10.1037/0735-7028.32.1.52.

30. Lawson $\mathrm{KL}$, Jonk Y, O'Connor H, Riise KS, Eisenberg DM, Kreitzer MJ. The impact of telephonic health coaching on health outcomes in a high-risk population. Glob Adv Health Med. 2013;2(3):40-7. https://doi.org/10.7453/ga hmj.2013.039.

31. Schmittdiel JA, Brown SD, Neugebauer R, Adams SR, Adams AS, Wiley D, et al. Health-plan and employer-based wellness programs to reduce diabetes risk: The kaiser permanente northern california next-d study. Prev Chronic Dis. 2013;10(1):E15.

32. Hamar B, Wells A, Gandy W, Haaf A, Coberley C, Pope JE, et al. The impact of a proactive chronic care management program on hospital admission rates in a German health insurance society. Popul Heath Manage. 2010; 13(6):339-45. https://doi.org/10.1089/pop.2010.0032.

33. Morello RT, Barker AL, Watts JJ, Bohensky MA, Forbes AB, Stoelwinder J. A telephone support program to reduce costs and hospital admissions for patients at risk of readmissions: lessons from an evaluation of a complex health intervention; 2016.

34. Scuffham PA, Byrnes JM, Pollicino C, Cross D, Goldstein S, Ng S-K. The impact of population-based disease management services on health care utilisation and costs: results of the CAPICHe trial. J Gen Intern Med. 2019; 34(1):41-8. https://doi.org/10.1007/s11606-018-4682-5.

35. Schwartz SM, Day B, Wildenhaus K, Silberman A, Wang C, Silberman J. The impact of an online disease management program on medical costs among health plan members. Am J Health Promot. 2010;25(2):126-33. https://doi.org/10.4278/ajhp.091201-QUAL-377.

36. Frost MC, Kuo ES, Harner LT, Landau KR, Baldassar K. Increase in Physical Activity Sustained 1 Year After Playground Intervention. Am J Prev Med. 2018;54(5, Supplement 2):S124-9.

37. Harris ZK. Private health insurance sponsored wellness programs: examining participation in the healthy lifestyle rewards financial incentives program on health care costs, utilization, and risk behaviors: ProQuest Information \& Learning; 2011.

38. Henry SL, Shen E, Ahuja A, Gould MK, Kanter MH. The online personal action plan: a tool to transform patient-enabled preventive and chronic care. Am J Prev Med. 2016;51(1):71-7. https://doi.org/10.1016/j.amepre.2015.11.014.

39. King HA, Gierisch JM, Williams JW Jr, Maciejewski ML. Effects of health plansponsored fitness center benefits on physical activity, health outcomes, and health care costs and utilization: a systematic review; 2012.

40. Maeng D, Pitcavage J, Tomcavage J, Steinhubl S. Can health insurance improve employee health outcome and reduce cost? An evaluation of Geisinger's employee health and wellness program. J Occup Environ Med. 2013;55(11):1271-5. https://doi.org/10.1097/JOM.0000000000000009. 
41. Coombs J. The role of nutrition screening and intervention programs in managed care. Manag Care Q. 1998;6(2):43-50.

42. Cheadle A, Atiedu A, Rauzon S, Schwartz PM, Keene L, Davoudi M, et al. A community-level initiative to prevent obesity: results from Kaiser

Permanente's healthy eating active living zones initiative in California. Am J Prev Med. 2018;54(5 Suppl 2):S150-s159. https://doi.org/10.1016/j.amepre.2 018.01.024.

43. McGill B, Bauman A, Phongsavan P, Grunseit AC, Lees D, Shepherd L, et al. Beyond weight loss: impact of a weight management programme for midolder Australians in private health insurance. Clin Obes. 2020;10(3):e12359. https://doi.org/10.1111/cob.12359.

44. Schwartz SM, Ireland C, Strecher V, Nakao D, Wang C, Juarez D. The economic value of a wellness and disease prevention program. Popul Heath Manage. 2010;13(6):309-17. https://doi.org/10.1089/pop.2009.0070.

45. Beck A, Scott J, Williams P, Robertson B, Jackson D, Gade G, et al. A randomized trial of group outpatient visits for chronically ill older $\mathrm{HMO}$ members: the cooperative health care clinic. J Am Geriatr Soc. 1997;45(5): 543-9. https://doi.org/10.1111/j.1532-5415.1997.tb03085.x.

46. Hinchman J, Beno L, Mims A. Kaiser Permanente Georgia's experience with operation zero: a group medical appointment to address pediatric overweight. Perm J. 2006;10(3):66-71. https://doi.org/10.7812/tpp/05-126.

47. National Institute for Health Research. Impacts of chronic disease prevention programs implemented by private health insurers: a systematic review. PROSPERO 2020 CRD42020145644. UK: National Institute for Health Research; 2020. https://www.crd.york.ac.uk/prospero/display_record.php? ID=CRD42020145644. Accessed 25 Feb 2021

\section{Publisher's Note}

Springer Nature remains neutral with regard to jurisdictional claims in published maps and institutional affiliations.

Ready to submit your research? Choose BMC and benefit from:

- fast, convenient online submission

- thorough peer review by experienced researchers in your field

- rapid publication on acceptance

- support for research data, including large and complex data types

- gold Open Access which fosters wider collaboration and increased citations

- maximum visibility for your research: over $100 \mathrm{M}$ website views per year

At $\mathrm{BMC}$, research is always in progress.

Learn more biomedcentral.com/submissions 